\title{
Obstetrical and perinatal outcome in adolescent pregnancy: a retrospective study at a tertiary care center in rural India
}

\author{
Arpitha Shruthi*, Sheela S. R., Vishnu Priya Kesani
}

\begin{abstract}
Department of Obstetrics and Gynecology, Sri Devaraj Urs Academy of Higher Education and Research, Kolar, Karnataka, India
\end{abstract}

Received: 25 March 2019

Accepted: 30 March 2019

*Correspondence:

Dr. Arpitha Shruthi,

E-mail: Apsy26.90@gmail.com

Copyright: (c) the author(s), publisher and licensee Medip Academy. This is an open-access article distributed under the terms of the Creative Commons Attribution Non-Commercial License, which permits unrestricted non-commercial use, distribution, and reproduction in any medium, provided the original work is properly cited.

\section{ABSTRACT}

Background: Adolescent pregnancy is a serious health and social problem worldwide. The aim of this study was to determine the obstetrical and perinatal outcomes of nulliparous adolescent pregnancies in a tertiary care centre in rural India.

Methods: This is a retrospective study conducted between April 2017 and March 2018.Adolescent primigravidae completing 28 weeks of gestation with singleton pregnancy were included in the study group. Primigravidae aged between 20 and 25 years were taken as a control group. The factors under study included obstetric complications and neonatal outcomes. The association was considered significant at P-value $<0.05$.

Results: 450 women were included in the study group and 460 to the control group. The incidence of adolescent pregnancy was $18.3 \%$ during the study period. The adolescent mothers had a significantly higher incidence of preeclampsia $(12.8 \%$ vs $8.4 \% ; p=0.03)$, eclampsia $(3.5 \%$ vs $1.5 \% ; p=0.01)$, preterm delivery $(18.6 \%$ vs $10.8 \% ; p$ $=0.0009)$, low birth weight $(39.1 \%$ vs $24.2 \% ; p=0.00001)$, very low birth weight babies $(13.7 \%$ vs $8.7 \% ; p=0.01)$ compared to control group. There was higher proportion of NICU admissions in adolescent group (20.8\% vs $12.3 \%$; $\mathrm{p}=0.0005)$ compared to control group. No significant difference was found regarding postpartum complications and still birth.

Conclusions: Adolescent pregnancy is associated with poorer feto-maternal outcomes. Regular antenatal visits, adequate nutritional supplementation and early detection of high-risk factors may contribute in decreasing the obstetric risk of childbirth in adolescent mothers.

Keywords: Adolescent pregnancy, Obstetric complications, Neonatal outcomes

\section{INTRODUCTION}

Pre-adult pregnancy is considered as high-hazard pregnancy and has gigantic negative financial effect at the individual dimension just as on the general public. As indicated by world health organization (WHO), adolescent pregnancy implies pregnancy somewhere in the range of 10 and 19 years old. In any case, insights into the statistics at the frequency between nations regularly gives rates per 1,000 adolescent matured 15-19 years. ${ }^{1}$ As indicated by WHO, 16 million adolescent moms conceive an offspring yearly and nine of each ten adolescent births are placed in low income countries. ${ }^{2}$ The pre-adult birth rate is most minimal in Japan and Denmark though higher rates are found in Nigeria and Republic of Congo.

As indicated by world bank information of 2013, there were 32 adolescent births for each 1,000 young ladies matured 15-19 in India. ${ }^{3}$ Deeply entrenched practice of child marriage, poor access to health care, poverty, and low literacy rates are mainly responsible for the high rate 
of adolescent pregnancy in India. Disputable perspectives exist with respect to the obstetric exhibitions of adolescent women. Some studies could not find any adverse pregnancy outcome among adolescent mothers with provision of high-quality maternity care., ${ }^{4,5}$

As per a study in Finland, where high quality care is accessible to all pregnant mothers, reported a higher danger of anemia, urinary tract disease, pyelonephritis, eclampsia, preterm conveyance, and antagonistic neonatal result among adolescent mothers with deficient antenatal consideration.

The investigation likewise revealed that there is a higher danger of pre-eclampsia among adolescent girls of 13-15 years of age. ${ }^{6}$ While in some different examinations, generally from developing nations, pre-eclampsia, eclampsia, anemia, premature labour, operative delivery, postpartum haemorrhage $(\mathrm{PPH})$, low-birth weight, still birth, and neonatal demise were observed to be related with adolescent pregnancy. ${ }^{7-10}$

In a vast multi-country study done by WHO in low income nations detailed that eclampsia, puerperal disease, preterm birth, low-birth weight, still birth, and early neonatal death were fundamentally higher among preadult mothers. ${ }^{10,11}$ It remains a matter of discussion that the amount of these obstetrical and perinatal intricacies is owing to age instead of accessibility, use and nature of wellbeing administrations, instructive dimension, conjugal status, race, and other socio-statistic factors.

Also, this distinction in unfavourable results might be because of the utilization of various strategies by various authors. Adolescent mothers face critical financial difficulties and the general cost of adolescent childbearing is colossal.

As per a United Nations report in 2013, the efficiency of India would be $\$ 7.7$ billion higher if adolescent pregnancy could be prevented. ${ }^{12}$ In a noteworthy move of wellbeing arrangement, government of India propelled a wellbeing program called the National Rural Health Mission (NRHM) in 2005 renamed as National Health Mission (NHM) in 2015, with the plan to lessen maternal death rate and baby death rate by giving totally free health care to all pregnant women and children up to 1 year of age alongside enhancement in social insurance conveyance framework.

The program additionally gives money related incentives to the mothers along with field level trained wellbeing specialists for emergency clinic conveyance. As a positive effect of the program, maternal death rate has decreased from 254 in 2005 to 178 in 2013, baby death rate has diminished from 58 out of 2005 to 40 of every 2013, and the rate of emergency clinic conveyance has altogether expanded. Our target of the investigation was to discover the obstetric complexities amid antepartum, intrapartum, and postpartum period and the perinatal result of adolescent primigravidae in India with the changing wellbeing situation.

\section{METHODS}

This is a retrospective study conducted at a tertiary care teaching hospital in rural India between April 2017 and March 2018. Adolescent primigravidae (age 15-19 years) completing 28 weeks of gestation with singleton pregnancy were included in the study group. Primigravidae aged between 20 and 25 years were taken as a control group. Age between 20-25 years was taken as the control group as this age group was considered low risk for pregnancy.

\section{Exclusion criteria}

- The factors excluded from the study group were, pregnancies complicated with overt diabetes, chronic hypertension, renal, thyroid, cardiac diseases.

The factors under study included demographic data, obstetric complications like pre-eclampsia, eclampsia, severe anaemia, mode of delivery, intrapartum and postpartum complications, neonatal outcomes including low birth weight, APGAR score at 1minute and 5 minutes, neonatal intensive care unit (NICU) admissions and still birth. The study protocol was approved by Sri Devaraj Urs Medical college institutional ethics committee.

\section{Statistical analysis}

The data were compiled and analyzed using the SPSS 19. For comparison, chi-square test and unpaired t-test were used for qualitative and quantitative data, respectively. The association was considered significant at $\mathrm{P}$-value $<0.05$.

\section{RESULTS}

Of 8,567 women who gave birth during the 1-year study period, 450 women were adolescents, giving a pregnancy rate of $18.3 \%$ during the study period. Mean age of the adolescents was 18.2 years.

(Table1) presents the demographic characteristics of the subjects and the antenatal care they had received (Table 1). In present study, all the mothers were married in both the groups.

The mean duration between the marriage and the conception was $3.5 \pm 1.2$ months in adolescent group and $8.6 \pm 1.5$ months in adult group. The low socioeconomic status was significantly higher in adolescent group in comparison to control group. In present study, approximately $76 \%$ adolescent mothers received antenatal care as compared to $84 \%$ in control group. 
Table 1: Demographic and antenatal backgrounds of study and control groups.

\begin{tabular}{|lll|}
\hline Variables & Age $(15-19$ years $)(\mathrm{N}=450)$ & Age $(20-25$ years $)(\mathrm{N}=460)$ \\
\hline Maternal age $($ Mean $)$ & 18.2 years & 22.4 years \\
\hline Antenatal care received & $76 \%$ & $84 \%$ \\
\hline Marital status (married) & $100 \%$ & $100 \%$ \\
\hline Time interval between marriage and conception & $3.5 \pm 1.2$ months & $8.6 \pm 1.5$ months \\
\hline Socioeconomic status & & $80 \%$ \\
\hline Below poverty line & $11 \%$ & $60 \%$ \\
\hline Low class & $68 \%$ & $32 \%$ \\
\hline Middle class & $20 \%$ & \\
\hline
\end{tabular}

Table 2: Represents the obstetrical characteristics of adolescent mothers and those of adult women aged 20-25 years.

\begin{tabular}{|llll|}
\hline Variables & Age (15-19 years) \% (n=450) & Age (20-25 years) \% (n=460) & P value \\
\hline Pre-eclampsia & 12.8 & 8.4 & 0.03 \\
\hline Eclampsia & 3.5 & 1.5 & 0.01 \\
\hline Antepartum haemorrhage & 1.21 & 0.9 & 0.75 \\
\hline Severe anemia & 2.42 & 3.03 & 0.42 \\
\hline Vaginal delivery & 71.5 & 70.3 & 0.73 \\
\hline Cesarean section & 24.8 & 25.7 & 0.8 \\
\hline Vaginal instrumental delivery & 3.6 & 4 & 0.75 \\
\hline Post-partum haemorrhage & 1.8 & 1.2 & 0.5 \\
\hline Preterm delivery & 18.6 & 10.8 & 0.0009 \\
\hline
\end{tabular}

Table 3: Represents the perinatal complications of the adolescent mothers and those of women age 20-25 years.

\begin{tabular}{|llll|}
\hline Variables & Age $(\mathbf{1 5}-\mathbf{1 9}$ years $) \%(\mathbf{n}=\mathbf{4 5 0})$ & Age $(\mathbf{2 0}-\mathbf{2 5}$ years) \% ( $\mathbf{n = 4 6 0 )}$ & P value \\
\hline Low birth weight & 39.1 & 24.2 & 0.00001 \\
\hline Very low birth weight & 13.7 & 8.7 & 0.01 \\
\hline APGAR $(<7$ in 1 minute $)$ & 12.1 & 13 & 0.78 \\
\hline APGAR $(<7$ in 5 minutes $)$ & 3.6 & 3.9 & 0.87 \\
\hline NICU admission & 20.8 & 12.3 & 0.0005 \\
\hline Still birth & 3.63 & 2.42 & 0.69 \\
\hline
\end{tabular}

(Table 3) represents the perinatal complications of the adolescent mothers and those of women aged 20-25 years. The incidence of preterm delivery was significantly higher in adolescent group $(\mathrm{P}=0.0009)$. The incidence of low-birth weight and very low birth weight was also higher in adolescent age group $(\mathrm{P}=0.00001$, $\mathrm{P}=0.01)$ and also the NICU admission $(\mathrm{P}=0.0005)$.

\section{DISCUSSION}

In developed nations, the rate of adolescent pregnancy has dropped over the last seventy years. Be that as it may, in developing nations like India adolescent pregnancy is as yet widespread with colossal sway on maternal and child wellbeing. Consequently, adolescent pregnancy turns into a general medical issue in India and necessities are to be handled on a need to need basis. In our investigation, all the pregnancies happened within the institution of marriage, and the larger part of them (80\%) got quality antenatal care in our tertiary emergency clinic. In present study, the level of adolescent mothers accepting antenatal consideration is higher than the past announced literary works from India. ${ }^{13}$ This is because of successful execution of NRHM (NHM) scheme in this area. Less unfriendly results among adolescents in present study might be because of the value of antenatal, intranatal, and postnatal consideration. The significance of value maternity care in decreasing the unfriendly results of adolescent pregnancy is featured in few reports. ${ }^{4,5,14}$

Low instructive dimension and poor financial status were observed to be essentially connected with adolescent mother as opposed to the adult populace. In a general public group with low education rate, individuals are probably going to pursue the deep-rooted social custom of offering a young lady in marriage at an early age. 
Destitution alongside discrimination amongst the sexes go about as an impetus for early marriage of young adolescents.

In present study, pre-eclampsia and eclampsia was observed to be essentially connected with adolescent mothers. This finding authenticates with past studies. ${ }^{7-9,15}$ Supposition with respect to the mode of delivery in adolescent pregnancy varies broadly. Various literatures cited that there is biological immaturity of the adolescent pelvis which causes cephalo-pelvic disproportion leading to an increase in caesarean section rate..$^{9,15,16}$ present study did not discover any increment in the rate of cesarean segment among adolescent mothers. This can be clarified that adolescent mothers bring forth small sized babies in comparison to other older mothers. Our finding concerning the mode of delivery is in opposition to the broadly held conviction that the adolescent mothers need cesarean delivery. A comparable view has been communicated in a few different studies. ${ }^{7,8,13,17}$

Authors found that adolescent pregnancy was related with expanded danger of preterm births which is predictable with different literatures. ${ }^{7,9,18}$ The system of preterm work among adolescent mothers is as yet hazy. $\mathrm{Be}$ that as it may, one physiological reason is the immaturity of the uterine and cervical blood supply in adolescent mothers which leads to increment in prostaglandin secretion prompting preterm labour. Another ongoing perspective is that, absence of legitimate menstrual preconditioning among adolescent mothers, interfere with the procedure of decidualization and trophoblastic intrusion that increases the risk of defective deep placentation that leads to preterm deliveries in adolescent primigravidae. This likewise halfway clarifies the expanded rate of pre-eclampsia among adolescent mothers. ${ }^{19}$

Other contributing elements may incorporate low financial status, young maternal age at first delivery, and hypertensive issue of pregnancy. The rate of low-birth weight babies in adolescent mothers was altogether higher in contrast with the mothers aged between 20-25 years. Being preterm babies, there are likewise higher occurrences of the NICU admission. This perception validates with different other literatures., ${ }^{7,9}$ The fundamental measure of interval between the wedding and also the conception was found to be less among adolescent mothers in comparison to the adult cluster. it's been reportable that there is increase fertility among the adolescent cluster. ${ }^{19}$

The impediment of the study is that, since the investigation was led in a tertiary emergency clinic where high caliber maternal and neonatal consideration offices were accessible the discoveries may not really mirror the circumstance of the entire populace. In addition, authors could exclude adolescent mother not exactly of 15 years who are in danger of serious obstetrical and neonatal complexities.
In the study area, pregnancy in this age group is uncommon. Confined instances of pregnancy do happen among more adolescent, yet for the most part without any father present and likely to finish up in lawful/illicit premature birth. Such adolescent mother infrequently comes to benefit human services office at a tertiary focus in light of the social shame related with it. Authors additionally did not assess the mental effect of pregnancy among adolescent mothers.

\section{CONCLUSION}

Adolescent pregnancy is associated with poorer fetomaternal outcomes. Regular antenatal visits, adequate nutritional supplementation and early detection of high risk factors may contribute in decreasing the obstetric risk of childbirth in adolescent mothers.

\section{Funding: No funding sources \\ Conflict of interest: None declared \\ Ethical approval: The study was approved by the Institutional Ethics Committee}

\section{REFERENCES}

1. World Health Organization. Adolescent Pregnancy: Issues in Adolescent Health and Development. Geneva: World Health Organization; 2004. (WHO discussion papers on adolescence). Accessed at: https://apps.who.int/iris/bitstream/handle/10665/429 03/9241591455_eng.pdf;jsessionid=06CA46C7496F 6E57BA7F6EF08DD3E2CE? sequence $=1$.

2. World Health Organization. Early marriages, adolescent and young pregnancies 2011. Geneva: World Health Organization. Accessed at: http://apps.who.int/gb/ebwha/pdf_files/EB130/B130 _12-en.pdf. Accessed on: February 19, 2019.

3. The World Bank. Adolescent Fertility Rate (births per 1000 women aged 15-19 years). United Nations Population Prospects. Accessed at: http://data.worldbank.org/indicator/SP.ADO.TFRT. Accessed from: February 19, 2019.

4. Raatikainen K, Heiskanen N, Verkasalo PK, Heinonen S. Good outcome of teenage pregnancies in high-quality maternity care. European $\mathrm{J}$ Public Health. 2005;16(2):157-61.

5. Blomberg M, Tyrberg RB, Kjølhede P. Impact of maternal age on obstetric and neonatal outcome with emphasis on primiparous adolescents and older women: a Swedish Medical Birth Register Study. BMJ Open. 2014;4(11):e005840.

6. Leppälahti S, Gissler M, Mentula M, Heikinheimo O. Is teenage pregnancy an obstetric risk in a welfare society? A population-based study in Finland, from 2006 to 2011. BMJ Open. 2013;3(8):e003225.

7. Briggs MM, Hopman WM, Jamieson MA. Comparing pregnancy in adolescents and adults: obstetric outcomes and prevalence of anemia. J Obstet Gynaecol Canada. 2007;29(7):546-55. 
8. Kumar A, Singh T, Basu S, Pandey S, Bhargava V. Outcome of teenage pregnancy. Indian $\mathrm{J}$ Pediat. 2007;74(10):927-31.

9. Tufail AM, Hashmi HA. Maternal and perinatal outcome in teenage pregnancy in a community-based hospital. Pak J surg. 2008;24(2):130-4.

10. Ganchimeg T, Mori R, Ota E, Koyanagi A, Gilmour S, Shibuya K, et al. Maternal and perinatal outcomes among nulliparous adolescents in low-and middleincome countries: a multi-country study. BJOG: An Int J Obstet Gynaecol. 2013;120(13):1622-30.

11. Ganchimeg T, Ota E, Morisaki N, Laopaiboon M, Lumbiganon $\mathrm{P}$, Zhang $\mathrm{J}$, et al. Pregnancy and childbirth outcomes among adolescent mothers: a World Health Organization multicountry study. BJOG: An Int J Obstet Gynaecol. 2014;121:40-8.

12. UNFPA. State of World Population 2013. Motherhood in Childhood. Facing the Challenge of Adolescent Pregnancy; 2013. Accessed at: http://www.unfpa.org/sites/default/files/pub-pdf/ENSWOP2013-final.pdf. Accessed from: February 19, 2019.

13. Ago BU, Abeshi S, Njoku C, Agban TU, Ekabua J. Obstetric outcomes of booked teenage pregnancies at University of Calabar teaching hospital, Nigeria. Adolesc Health Med Ther. 2012;3:105-9.

14. Sulaiman S, Othman S, Razali N, Hassan J. Obstetric and perinatal outcome in teenage pregnancies. South African J Obstet Gynaecol. 2013;19(3):77-80.
15. WHO. Expert Committee Report. Physical Status: The Use and Interpretation of Anthropometry. Technical report Series 854, Geneva: World Health Organisation; 1995. Lao TT, Ho LF. Obstetrics outcomes of teenage pregnancy. Hum Reprod. 1998;13(11):3228-32.

16. Iqbal F, Azad S, Tayyab R. Obstetrical and fetal outcome in teen age primigravida. Annals of King Edward Medical University. 2004;10(4).

17. Hidalgo LA, Chedraui PA, Chávez MJ. Obstetrical and neonatal outcome in young adolescents of low socio-economic status: a case control study. Archiv Gynecol Obstet. 2005;271(3):207-11.

18. Mukhopadhyay P, Chaudhuri RN, Paul B. Hospitalbased perinatal outcomes and complications in teenage pregnancy in India. $\mathbf{J}$ Health Population Nutrit. 2010;28(5):494.

19. Brosens I, Benagiano G. Menstrual preconditioning for the prevention of major obstetrical syndromes in polycystic ovary syndrome. Am J Obstet Gynecol. 2015;213(4):488-93.

Cite this article as: Shruthi A, Sheela SR, Kesani VP. Obstetrical and perinatal outcome in adolescent pregnancy: a retrospective study at a tertiary care center in rural India. Int J Reprod Contracept Obstet Gynecol 2019;8:1733-7. 